\title{
CARACTERIZAÇÃO DE LEITE BOVINO UTILIZANDO ULTRA-SOM E REDES NEURAIS ARTIFICIAIS
}

\author{
Sergio Luiz Sousa Nazário* \\ sergionazario@yahoo.com.br \\ Flávio Buiochi ${ }^{\ddagger}$ \\ fbuiochi@usp.br \\ Cláudio Kitano* \\ kitano@dee.feis.unesp.br \\ Jacira dos Santos Isepon ${ }^{\dagger}$ \\ jaciradagr.feis.unesp.br \\ Julio Cezar Adamowski ${ }^{\ddagger}$ \\ jcadamow@usp.br \\ Ricardo Tokio Higuti* \\ tokio@dee.feis.unesp.br \\ * Departamento de Engenharia Elétrica - Unesp \\ Avenida Brasil, 56, CEP 15385-000, Ilha Solteira, SP \\ $\dagger$ Departamento de Fitotecnia, Tecnologia de Alimentos e Sócio-Economia - Unesp \\ Avenida Brasil, 56, CEP 15385-000, Ilha Solteira, SP \\ ‡Departamento de Mecatrônica e de Sistemas Mecânicos - EPUSP \\ Avenida Prof. Mello Moraes, 2231, CEP 05508-900, São Paulo, SP
}

\section{ABSTRACT}

Characterization of Bovine Milk Using Ultrasound and Artificial Neural Networks

The quality control of food products is very important to determine their composition and nutrition facts, and to detect eventual frauds and adulterations in raw or industrialized products. For example, bovine milk can be adulterated by addition of foreign products, in order to increase the volume or to extend the expiration date, with economic and sanitary impacts. This work presents the characterization of milk using ultrasound and neural networks techniques. An ultrasonic measurement cell was used to obtain the propagation velocity, attenuation coefficient and density of milk liquid samples with different fat contents and added water. Samples were calibrated by using conventional methods employed in the dairy industry. Artificial neural networks were designed to output the fat content and added water of samples from the information of the experimental parameters measured by

Artigo submetido em 17/11/2008 (Id.: 00921)

Revisado em 05/04/2009, 26/05/2009

Aceito sob recomendação do Editor Associado Prof. Sebastian Yuri Cavalcanti Catunda
\end{abstract}

the cell. The algorithm resulted in more than $95 \%$ of correct classification, with resolution of $0.1 \%$ in the determination of fat content. For the determination of added water, the resolution was $1 \%$ (between 1 and $10 \%$ of added water) and $10 \%$ (between 10 and $60 \%$ of added water).

KEYWORDS: Ultrasound, Artificial Neural Networks, Milk.

\section{RESUMO}

O controle da qualidade de alimentos é muito importante para determinar as suas composições e teor nutritivo, bem como para detectar eventuais fraudes e adulterações, sejam elas em matérias-primas ou produtos industrializados. Por exemplo, o leite bovino pode sofrer adulteração por adição de outros produtos, com o objetivo de aumentar o volume ou prolongar o prazo de validade, causando prejuízos econômicos e sanitários. Este trabalho apresenta um estudo sobre a caracterização de leite fluido utilizando técnicas de ultra-som e redes neurais artificiais. Utilizou-se uma célula de medição de propriedades de líquidos por ultra-som para obter dados de densidade, velocidade de propagação e coeficiente 
de atenuação, que foram relacionados com as concentrações de gordura e água adicionada em amostras de leite bovino, obtidas com métodos convencionais utilizados em laticínios, para efeito de calibração das amostras. Esses dados foram utilizados para projetar redes neurais artificiais, que fornecem na saída o teor de gordura e a quantidade de água adicionada ao leite, a partir dos parâmetros medidos pela célula de medição. As redes neurais desenvolvidas resultaram em mais de $95 \%$ de amostras classificadas corretamente, com uma resolução de $0,1 \%$ na determinação da quantidade de gordura. Para quantidade de água adicionada, a resolução foi de $1 \%$ para 1 a $10 \%$ de água adicionada, e resolução de 5\% para quantidade de água adicionada de 10 a $60 \%$.

PALAVRAS-CHAVE: Ultra-som, Redes Neurais Artificiais, Leite.

\section{INTRODUÇÃO}

O controle da qualidade dos alimentos consumidos pela população é muito importante, para averiguar seus teores nutritivos e composição, por exemplo. Uma outra implicação importante é na detecção da deterioração ou adulteração dos alimentos, sejam eles a matéria-prima ou o produto industrializado ou processado. Em particular, tem-se noticiado na mídia com certa frequência a adulteração de leite bovino, na forma de adição de substâncias para aumentar o volume ou para prolongar o prazo de validade. A detecção desse tipo de ação é muito importante, pois os produtos adulterados trazem riscos à saúde da população, além das consequências econômicas.

O leite pode ser descrito, sob o ponto de vista biológico e físico-químico, como um líquido constituído por água, gordura, proteína, lactose e minerais. Na adulteração do leite, pode-se acrescentar, por exemplo, água ou soro de leite, modificando-se a densidade e o teor de gordura. Outros produtos químicos podem ser adicionados para mascarar a variação dos parâmetros do leite, dificultando a detecção da adulteração.

Normalmente, as caracterizações de leite líquido são feitas em laboratórios existentes nos próprios laticínios, em que se medem propriedades como o teor de gordura, proteína, sólidos totais e água adicionada, entre outros. Em geral, é utilizado um equipamento para cada propriedade de interesse, e as técnicas podem envolver a manipulação de produtos químicos, ser demoradas e destrutivas. Por outro lado, apresentam resolução e acurácias que são padronizadas e aceitas na indústria.

Uma alternativa a ser considerada é o uso de ultra-som para caracterizar líquidos, que é uma técnica relativamente simples, não-destrutiva e pode ser usada on-line. Aplicações de ultra-som na área de alimentos podem ser distinguidas a partir de técnicas de alta e baixa potência (Povey, 1997). As técnicas de alta potência são em geral de baixa frequiência (20 a $100 \mathrm{kHz}$ ), podendo implicar em modificações físicoquímicas do material. As técnicas de alta freqüência (acima de $500 \mathrm{kHz}$ ) e baixa potência são utilizadas para caracterização de alimentos através da determinação de concentração, densidade, tamanho de partícula, fluxo e dimensões, entre outras aplicações (McClements, 1995; Mason et al., 1996; Javanaud, 1988). Algumas aplicações específicas do ultra-som no setor de laticínios são encontradas na literatura para determinar o teor de gordura (Bacaneli, 1998; Dorabiato et al., 2006) e existem estudos de métodos para determinar a coagulação de leite para fabricação de queijo (Gunasekaran and Ay, 1994; Benedito et al., 2002). Elvira et al. (2005) usaram o ultra-som para detectar micróbios em leite tipo UHT (Ultra High Temperature) embalado, através do monitoramento da velocidade de propagação.

Miles et al. (1990) investigaram o fenômeno da atenuação acústica no leite proveniente de dois efeitos: perdas intrínsecas e perdas ligadas às partículas de gordura presentes no meio. Concluíram que as perdas causadas por essas partículas são proporcionais à concentração de gordura presente na amostra. Bacaneli (1998) verificou a relação entre parâmetros acústicos como velocidade de propagação da onda, atenuação e densidade, em função do teor de gordura presente no leite. Foram obtidas curvas de calibração, que foram utilizadas para relacionar esses parâmetros acústicos com as características do leite em função da temperatura. Dukhin et al. (2005) utilizam um espectrômetro acústico que trabalha entre 3 e $100 \mathrm{MHz}$, e medem a atenuação do som em amostras de produtos lácteos (leite, manteiga) com diferentes concentrações de gordura e em função da temperatura. Segundo os autores, devido às propriedades das amostras, para frequências acima de $50 \mathrm{MHz}$ as perdas intrínsecas são predominantes em relação às perdas térmicas (sendo as perdas viscosas desprezíveis), e portanto essa faixa de frequência seria mais adequada para medir a atenuação sem os efeitos de variação do tamanho de partículas. No entanto, não se faz uma classificação das amostras, apenas se levantam curvas que mostram a dependência da atenuação com o teor de gordura, temperatura e frequência de operação.

Uma limitação em se trabalhar somente com curvas de calibração pode surgir devido à possibilidade de uma amostra de leite adulterado e uma amostra de leite sem adulteração possuírem um mesmo valor de velocidade de propagação devido a diferentes teores de gordura, por exemplo, o que pode provocar interpretações erradas. Portanto, o uso de técnicas mais elaboradas para a análise dos resultados é necessária. Entre elas, redes neurais artificiais têm sido aplicadas em diversos problemas de classificação. 
Redes Neurais Artificiais (RNAs) são sistemas paralelos e distribuídos, compostos por unidades de processamento simples, chamados neurônios, que calculam determinadas funções matemáticas. Na maioria dos modelos estas conexões estão associadas a pesos, os quais armazenam o conhecimento representado no modelo e servem para ponderar a entrada recebida por cada neurônio da rede (Braga et al., 2000).

Redes neurais artificiais são uma excelente alternativa para resolução de problemas de classificação, uma vez que o processamento é estruturalmente paralelo e apresenta diversas funcionalidades, como adaptabilidade, tolerância à falha e abstração, aliando-as à velocidade de resposta, entre outros. Além disso, o que torna as redes neurais uma técnica interessante para o problema é a capacidade de ser projetada para generalizar e produzir um mapeamento de entrada-saída correto, mesmo quando a entrada for um pouco diferente dos exemplos usados para treinar a rede (Braga et al., 2000).

Existem diversos exemplos de aplicação de redes neurais, juntamente com sinais provenientes de sensores, para classificar produtos na área alimentícia. Chandraratne et al. (2008) fazem a classificação de cortes de carne de cordeiro, utilizando imagens obtidas por meio de câmeras e RNAs, em função de teor de gordura, quantidade de osso, textura, etc. A classificação de amostras de chá verde líquido utilizando sensores do tipo nariz ou língua eletrônica também foi realizada utilizando RNAs (Chen et al., 2008; Yua et al., 2008). Lewis et al. (2007) utilizam um sensor a fibra óptica e técnicas de RNAs para avaliar a coloração de alimentos durante o cozimento e para o monitoramento de água.

Para o caso de caracterização e classificação de amostras de leite, não se encontraram na literatura métodos que empregam ultra-som e redes neurais. Alguns trabalhos envolvem a utilização de outros tipos de sensores, com classificação dos resultados por meio de redes neurais. Por exemplo, Winquist et al. (1998) utilizam uma língua eletrônica, cujos sensores são baseados em eletrodos que medem a condutividade do meio. O sensor é utilizado para detectar crescimento microbiano no leite, e os dados são posteriormente processados por uma rede neural artificial. Brudzewski et al. (2004) utilizam um sensor de gás como nariz eletrônico para classificar amostras de leite submetidos a diferentes tipos de tratamentos térmicos e pasteurização. Os elementos voláteis presentes no leite dependem do tipo de tratamento realizado, que são detectados pelos sensores e classificados pelas redes neurais. No caso, foram utilizadas amostras com teores de gordura iguais a $0,0,5,2$ e $3,5 \%$. Pertencentes ao mesmo grupo de trabalho, Ciosek et al. (2006) utilizam o mesmo tipo de rede neural, mas com uma língua eletrônica, baseada em eletrodos, para classificar amostras de leite de diferentes marcas e teores de gordura. São avaliadas amostras com dois teores de gordura: 2 e $3,2 \%$.
Na revisão da literatura não se encontraram problemas de caracterização e classificação de amostras de leite com o intuito de detectar adulterações, como a adição de água. Além disso, os estudos realizados por outros autores não contemplam uma variação mais detalhada nas propriedades das amostras (teor de gordura e água adicionada), com o objetivo de determinar a acurácia e resolução do método. Esses pontos são analisados neste trabalho, no qual se mostra a aplicação de técnicas de ultra-som e de redes neurais para classificar amostras de leite líquido em função do teor de gordura e de água adicionada, com o objetivo de detectar adulterações. São apresentados a seguir a célula de medição de propriedades de líquidos, a preparação e calibração de amostras, os resultados com ultra-som, o projeto e testes com as redes neurais artificiais.

\section{CÉlULA DE MEDIÇÃo POR ULTRA- SOM}

A célula de medição por ultra-som utilizada neste trabalho foi originalmente concebida para a medição de densidade de líquidos (Adamowski et al., 1995). Depois foi aperfeiçoada para caracterização de líquidos (Higuti and Adamowski, 2002; Higuti et al., 2007), apresentando maior acurácia na medição das propriedades como a densidade, velocidade de propagação e atenuação do som na amostra.

Nesta seção se faz uma descrição resumida do funcionamento da célula, e maiores detalhes são encontrados nas referências citadas anteriormente. A figura 1 mostra um esquema da célula de medição por ultra-som, apresentando três partes: transdutor duplo-elemento (TDE), câmara de amostra e refletor. O TDE é, por sua vez, composto por um transdutor emissor piezelétrico compósito, uma linha de retardo de acrílico, um receptor de grande abertura de $\mathrm{P}(\mathrm{VDF}-\mathrm{TrFE})$ (Polivinilideno de Flúor Tri-Flúor Etileno) e uma linha de retardo de vidro. $\mathrm{O}$ emissor é excitado com um pulso elétrico estreito, e o pulso acústico resultante propaga-se pelas linhas de retardo e amostra, atingindo o receptor como os sinais de eco $a_{T}(t)$, $a_{1}(t), a_{2}(t)$ e $a_{3}(t) . Z_{i}$ e $L_{i}$ são a impedância acústica e o comprimento da linha de retardo de acrílico $(i=1)$ e da amostra $(i=2)$, respectivamente.

Por meio dos sinais de eco (vide figura 2) e do conhecimento de algumas características da célula, podem ser medidas a densidade, a velocidade de propagação e o coeficiente de atenuação da onda acústica que se propaga pela amostra. A velocidade de propagação pela amostra é medida por meio da diferença de tempo $\left(\Delta t_{12}\right)$ entre os sinais de eco $a_{1}(t)$ e $a_{2}(t)$ e do conhecimento prévio do comprimento da câmara de amostra, $L_{2}$ : 


$$
c_{2}=\frac{2 L_{2}}{\Delta t_{12}}
$$

A densidade da amostra é obtida a partir da medição do coeficiente de reflexão na interface linha de retardo de vidro/amostra: $R_{12}=\left(Z_{2}-Z_{1}\right) /\left(Z_{2}+Z_{1}\right)$, que por sua vez é mensurado a partir dos sinais de eco, utilizando o chamado método da energia (Higuti and Adamowski, 2002). A densidade da amostra é então calculada por:

$$
\rho_{2}=\frac{\rho_{1} c_{1}}{c_{2}} \frac{1+R_{12}}{1-R_{12}},
$$

na qual a densidade da linha de retardo de vidro $\rho_{1}$ é conhecida e a velocidade de propagação $c_{1}$ pode ser medida por meio do conhecimento do comprimento $L_{1}$ e da medição do intervalo de tempo entre $a_{T}(t)$ e $a_{1}(t)$.

O coeficiente de atenuação é medido por:

$$
\alpha_{2}(f)=\frac{1}{2 L_{2}} \log \left[\frac{\left|A_{1}(f)\right|}{\left|A_{2}(f)\right|} \frac{1-R_{12}^{2}}{R_{12}} R_{23}\right],
$$

na qual $A_{i}(f)$ são os espectros dos sinais de eco $a_{i}(t)$, e $R_{23}$ é o coeficiente de reflexão na interface entre a amostra e o refletor.

A temperatura exerce uma influência importante sobre o funcionamento da célula e os parâmetros medidos, por isso os experimentos descritos a seguir foram conduzidos com temperatura controlada. Como a velocidade de propagação tem uma dependência desprezível da freqüência, o intervalo de tempo medido pelo método da correlação cruzada representa uma média da velocidade em torno da frequência de operação do transdutor emissor, que no caso situa-se entre 4 e $6 \mathrm{MHz}$. Por outro lado, o coeficiente de atenuação tem uma variação significativa com a frequência, motivo pelo qual foi explicitada sua dependência com $f$ em (3).

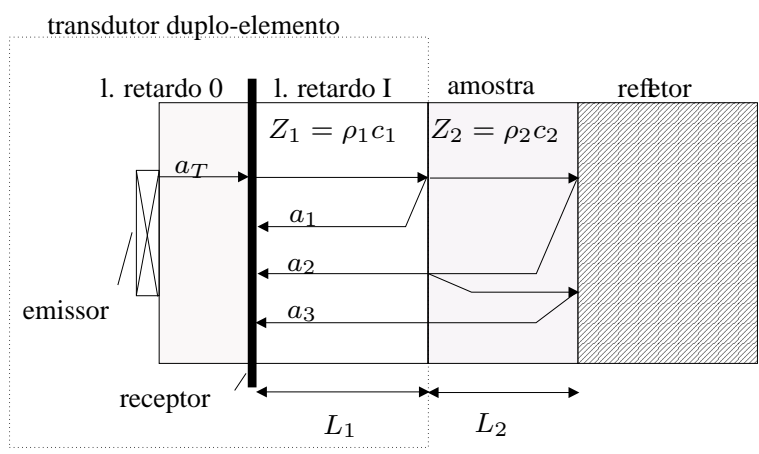

Figura 1: Esquema da célula de medição.

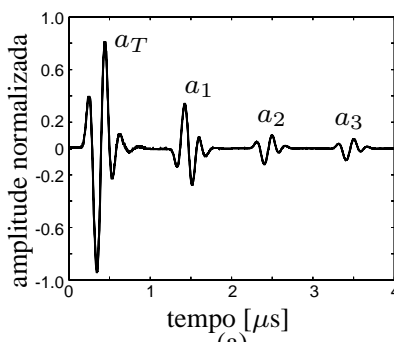

(a)

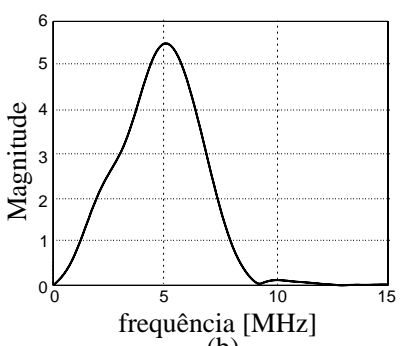

(b)
Figura 2: Exemplo de sinais de eco captados pelo receptor: (a) domínio do tempo e (b) espectro de magnitude de um sinal de eco.

\subsection{Procedimento experimental}

\subsubsection{Preparação das Amostras}

Foram preparadas amostras calibradas utilizando leite tipo UHT (Ultra High Temperature), que é homogeneizado e apresenta distribuição e formato de partículas de gordura regulares. Para obter amostras com diferentes teores de gordura, foram feitas diluições de leite integral (que possui teor de gordura aproximadamente igual a 3,0\%) utilizando leite desnatado (teor de gordura de cerca de 0,5\%). As amostras assim obtidas foram aferidas utilizando uma técnica convencionalmente utilizada em laboratórios de tecnologia de alimentos, chamado método ácido-butirômetro de Gerber (Behmer, 1984).

Com o intuito de verificar eventuais adulterações, foram preparadas amostras com diferentes teores de água adicionada, através da diluição de leite integral com água destilada. As amostras foram aferidas com o método de crioscopia, em que se mede o ponto de congelamento da amostra. Quanto maior o teor de água adicionada, mais alta é a temperatura de congelamento do leite.

Foram medidas também as densidades das amostras com métodos diferentes do ultra-sônico, utilizando um termolactodensímetro, específico para medições de amostras de leite, e o método do picnômetro, em que se mede a massa de amostra em um volume conhecido. Para isso, e também para as diluições de amostras, foi utilizada uma balança de precisão, com resolução de $0,01 \mathrm{~g}$.

\subsubsection{Montagem experimental}

O sistema de excitação, recepção, aquisição e processamento dos dados está representado na figura 3. A célula de medição é colocada em um banho termostático (Marconi, modelo MA-184) para controle da temperatura. Sensores de temperatura resistivos de platina (Pt-100, marca Minco) são colocados em diversos pontos da célula, como nas linhas de retardo 
e câmara de amostra. Os sinais dos sensores são digitalizados por uma placa de aquisição com elevada resolução (National Instruments NI-4351, 24 bits) e um programa escrito em MATLAB faz o controle da placa e a leitura dos dados. A célula de medição é conectada a um pulsador/receptor de ultrasom (Panametrics 5077PR), que excita o transdutor emissor com um pulso estreito e amplifica o sinal captado pelo receptor. O sinal amplificado é digitalizado por um osciloscópio (Tektronix TDS2022, 8 bits) e enviado ao computador via interface GPIB. No computador, programas escritos em MATLAB fazem o controle dos instrumentos e o processamento dos dados.

Numa aplicação prática, a parte eletrônica (pulsador/receptor, aquisição e processamento de dados) poderia ser substituída por sistemas dedicados, reduzindo assim o custo e o volume do equipamento, que é um fator importante para aplicação em pequenos laticínios. A questão do controle da temperatura pode ser incluída no projeto da célula de medição, e uma alternativa seria trabalhar numa temperatura superior à ambiente e utilizar uma resistência elétrica para manter a temperatura no ponto desejado.

Cada dado de velocidade, atenuação e densidade foi obtido a partir de cinco aquisições de formas de onda, obtendo-se as médias e desvios-padrão. No osciloscópio digital também foi utilizado o recurso de médias nas formas de onda, para reduzir o ruído aleatório.

\subsection{Resultados}

A seguir se apresentam os resultados das medições da velocidade de propagação $(c)$, coeficiente de atenuação $(\alpha)$ e densidade $(\rho)$ para amostras com diferentes concentrações de gordura $\left(\phi_{g}\right)$ e água adicionada $\left(\phi_{a}\right)$. Esses resultados são utilizados posteriormente para alimentar as redes neurais, nas fases de treinamento e testes. Os resultados, mostrados na forma gráfica, servem para explicitar a dependência dos parâmetros medidos $\left(c, \alpha\right.$ e $\rho$ ) em função de $\phi_{g}$ e $\phi_{a}$.

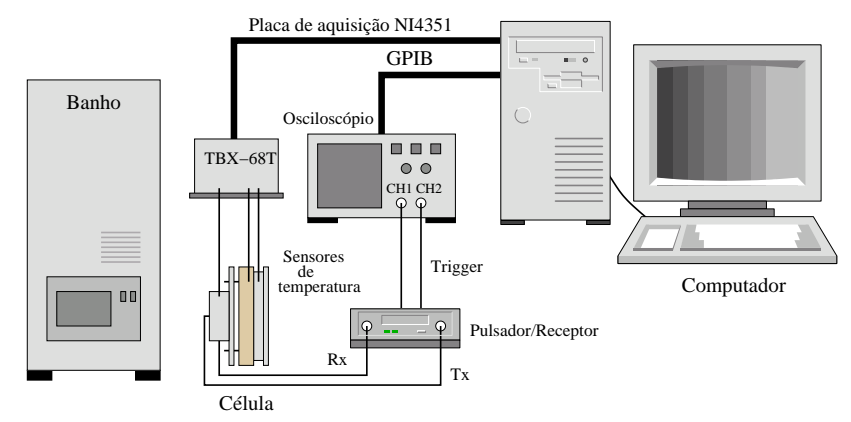

Figura 3: Esquema da montagem experimental.
Uma observação em relação à medição da atenuação é que os valores apresentados são normalizados em relação a um valor específico (em geral, com menor atenuação no conjunto de amostras), representando uma diferença de atenuação, ou atenuação em excesso, representada por $\Delta \alpha$.

\subsubsection{Calibração da célula}

Para medições com elevada exatidão da velocidade de propagação, o comprimento da câmara de amostra $\left(L_{2}\right)$ deve ser conhecido e corrigido em função da temperatura $T$, por meio de uma calibração da célula. Essa variação é causada pelas expansões e contrações térmicas dos diferentes materiais que compõem a célula. Para isso, se utiliza como amostra água destilada, que possui a velocidade de propagação e densidade conhecidas em função da temperatura. De acordo com calibrações mais detalhadas realizadas em outro trabalho (Higuti et al., 2007), verificou-se que a variação em $L_{2}$ é linear com a temperatura, com taxa de variação do comprimento da câmara de amostra com a temperatura $\left(\Delta_{L}\right)$, igual a $0,2 \mu \mathrm{m} /{ }^{\circ} \mathrm{C}$. Dessa forma, medindo-se o comprimento da câmara de amostra $\left(L_{2 c a l}\right)$ em uma determinada temperatura de calibração $T_{\text {cal }}$, o comprimento em uma outra temperatura $T$ é dado por:

$$
L_{2}(T)=L_{2 c a l}+\left(T-T_{c a l}\right) \Delta_{L}
$$

Nessa calibração também é mensurada a densidade da água destilada, cujo resultado também é comparado com valores tabelados para verificar o correto funcionamento da célula de medição.

\subsubsection{Teor de gordura}

Utilizando as amostras de leite calibradas, foram realizados diversos experimentos, com o teor de gordura variando entre 0,5 e 3,0\%. Na figura 4, mostra-se a velocidade de propagação em função da temperatura para as diferentes concentrações de gordura. Nota-se que a velocidade depende fortemente da temperatura e diminui para concentrações de gordura maiores. No entanto, a variação entre as velocidades de diferentes amostras permanece aproximadamente constante na faixa de temperatura mostrada no gráfico. Portanto, uma maneira de reduzir o efeito da temperatura seria medir a velocidade da amostra em relação à velocidade de uma amostra de referência. Os desvios nas medidas de velocidade são da ordem de $1 \mathrm{~m} / \mathrm{s}$, ou menores que $0,1 \%$.

Não há variação considerável no coeficiente de atenuação em função da temperatura, mas há uma maior dependência com a frequência do ultra-som. Na figura 5, apresenta-se o coeficiente de atenuação para diferentes teores de gordura, em função da frequência e para a temperatura de $27^{\circ} \mathrm{C}$. As li- 
nhas pontilhadas são aproximações lineares em função da frequência. Para frequências mais altas, os valores diferem mais entre si, e tem-se um maior poder de discriminação pelo uso da atenuação nessas condições. No caso do transdutor utilizado, a faixa de operação $(-3 \mathrm{~dB})$ fica limitada entre 4 e $6 \mathrm{MHz}$, aproximadamente. O uso de transdutores com banda mais larga pode introduzir mais informação em outras frequências, sobretudo as maiores. Os desvios das medidas são de cerca de $1 \mathrm{~Np} / \mathrm{m}$.

A densidade em função do teor de gordura é apresentada na figura 6. Nota-se uma pequena diminuição da densidade com o aumento do teor de gordura. Como as variações são também pequenas em comparação com os desvios nas medidas, encontra-se uma dificuldade no uso da densidade nesse tipo de caracterização.

\subsubsection{Teor de água adicionada}

Na figura 7, mostra-se a velocidade de propagação em função da temperatura para diferentes teores de água adicionada. As velocidades aumentam com a temperatura, mas diminuem com o aumento do teor de água. É interessante notar que o aumento do teor de água adicionada diminui o teor de gordura do leite, devido à maior diluição deste. Por outro lado, observando a curva da velocidade em função da temperatura para diferentes teores de gordura (figura 4), nota-se que, ao diminuir o teor de gordura, a velocidade aumenta. Essa dificuldade em relacionar os diversos parâmetros acústicos com as propriedades do leite justifica a utilização das redes neurais para a classificação das amostras.

Com o aumento do teor de água, o coeficiente de atenuação e a densidade diminuem, como mostrado nas figuras 8 e 9 , respectivamente, na temperatura de $24,5^{\circ} \mathrm{C}$. A discriminação de baixos teores de água é dificultada pelas pequenas vari-

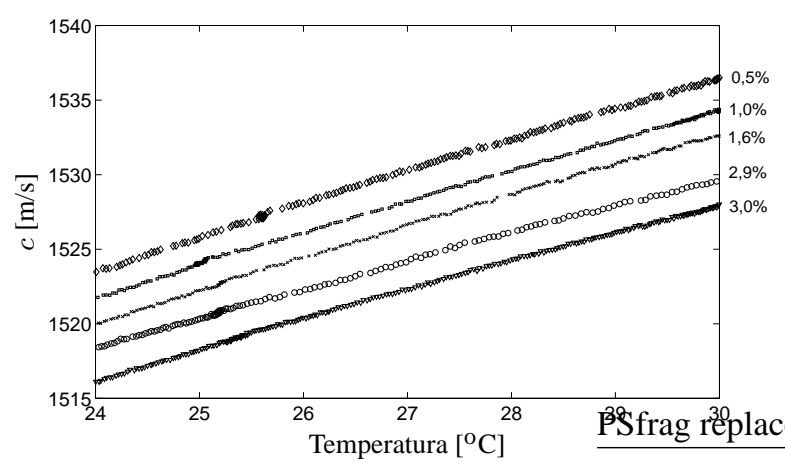

Figura 4: Velocidade de propagação no leite UHT em função da temperatura. Cada curva corresponde a diferentes concentrações de gordura, que estão indicadas no lado direito do gráfico.

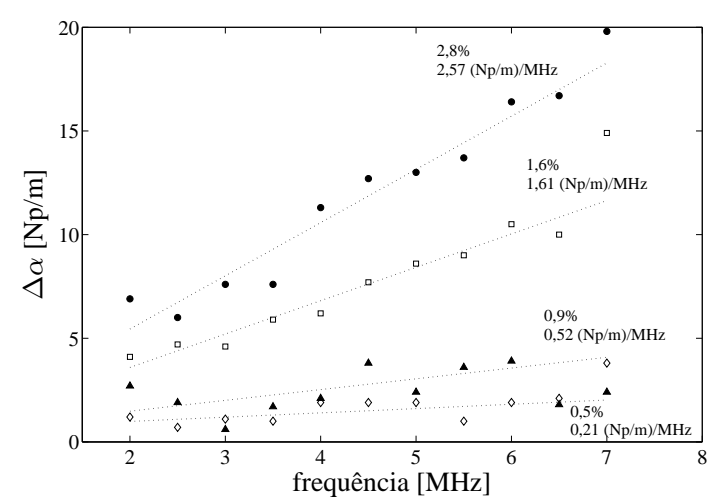

Figura 5: Coeficiente de atenuação no leite UHT em função da frequência, na temperatura de $27^{\circ} \mathrm{C}$.

ações nessa região e aos desvios das medidas, mas se verá mais adiante que o uso combinado de diversos parâmetros medidos pela célula, mais a temperatura, levam à identificação correta das amostras de leite.

\section{REDES NEURAIS}

O problema aqui abordado enquadra-se na classificação de padrões, ou seja, ao se apresentar um determinado conjunto de dados à rede neural artificial, deve-se ter como resposta a classe a que ele pertence. Os dados obtidos pela célula de medição (velocidade e coeficiente de atenuação acústica em função da temperatura) são utilizados por uma rede neural do tipo MLP (Multi-Layer Perceptron) para classificar os teores de gordura do leite UHT.

Na figura 10, apresenta-se a configuração de saída para a rede projetada para detecção da quantidade de gordura no leite, na qual utilizou-se uma configuração com 5 nodos na camada de entrada, representando os dados de temperatura $(T)$, velocidade de propagação $(c)$ e atenuação da onda nas frequências de $4 \mathrm{MHz}\left(\alpha_{1}\right), 5 \mathrm{MHz}\left(\alpha_{3}\right)$ e $6,5 \mathrm{MHz}\left(\alpha_{3}\right)$. Em geral, a

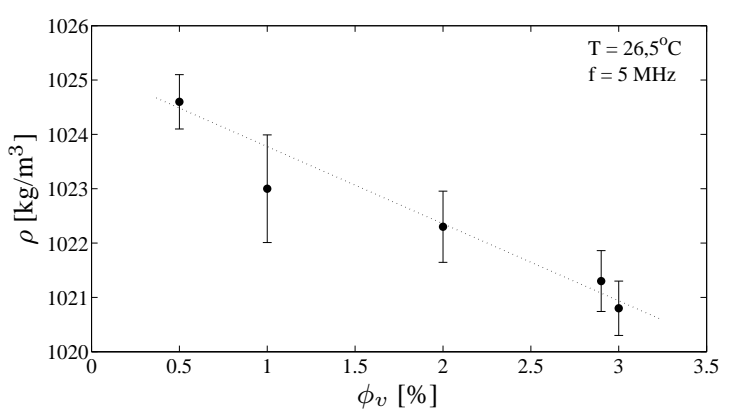

Figura 6: Densidade do leite UHT em função da concentração de gordura, na temperatura de $26,5^{\circ} \mathrm{C}$. 


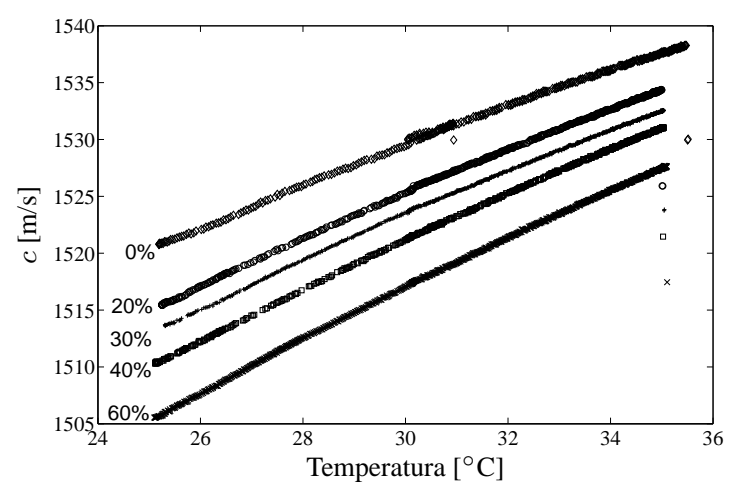

Figura 7: Velocidade de propagação no leite UHT com diferentes quantidades de água adicionada em função da temperatura.

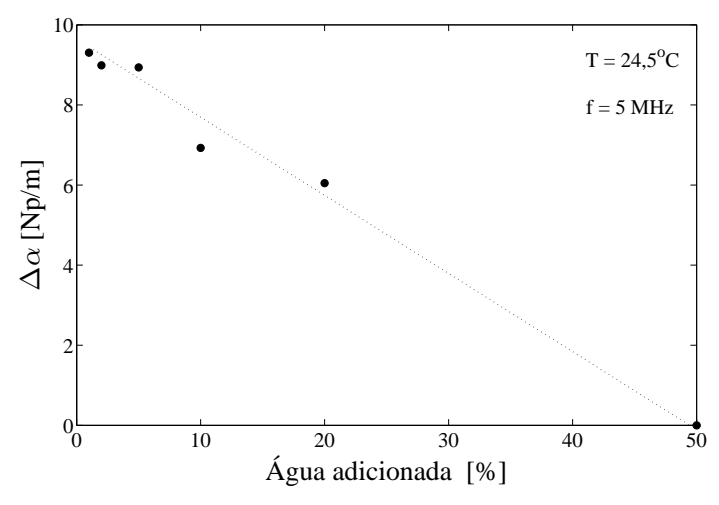

Figura 8: Coeficiente de atenuação no leite UHT em função da quantidade de água adicionada, na temperatura de $24,5^{\circ} \mathrm{C}$.

variação da densidade de um líquido, em função de um parâmetro de interesse, constitui uma importante propriedade uti-

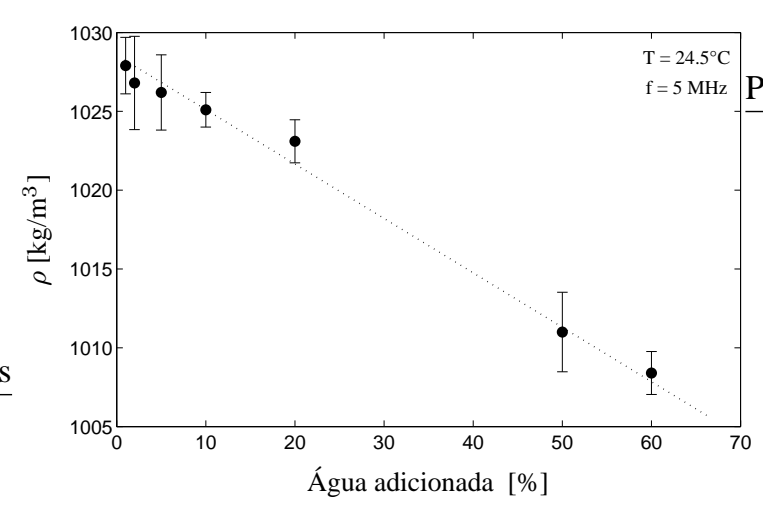

Figura 9: Densidade para o leite UHT integral em função de água adicionada, na temperatura de $24,5^{\circ} \mathrm{C}$. lizada para sua caracterização (Adamowski et al., 1995). Entretanto, no caso específico do leite, observou-se que a densidade não apresentou variação significativa para pequenos teores de gordura e de água adicionada, e então decidiu-se por não utilizar esse parâmetro como entrada das redes neurais. Foram utilizados vinte e seis nodos na camada de saída, representando os teores de gordura presentes no leite, entre 0,5 e $3,0 \%$, com resolução de $0,1 \%$.

Uma outra rede neural foi projetada para detectar adulteração de amostras de leite por adição de água na faixa de $1 \%$ até $60 \%$, com uma resolução de $1 \%$ entre 1 e $10 \%$ de água adicionada, e resolução de $5 \%$ entre 10 e $60 \%$ de água adicionada. Esses valores foram utilizados inicialmente, considerando a resolução de alguns equipamentos comerciais. Para esse problema, foram utilizadas arquiteturas com cinco nodos na camada de entrada assim como a configuração utilizada para obtenção da quantidade de gordura, 21 nodos na camada de saída e uma camada oculta. Na figura 11, apresenta-se a configuração de saída para a rede projetada para detecção de água adicionada ao leite.

O dimensionamento das redes foi realizado através do método de refinamento manual, estudando os parâmetros e escolhendo a melhor combinação testada. Nesta seleção podem existir situações nas quais podem-se determinar soluções diferentes para o mesmo problema, e com uma mesma eficiência, mas com parâmetros diferentes. Para a definição dos parâmetros da rede, foram variadas grandezas como a quantidade máxima de interações, o número de neurônios na camada intermediária, a taxa de aprendizado e a constante de momento.

Foram testadas redes MLP com 26, 40 e 52 nodos na ca-

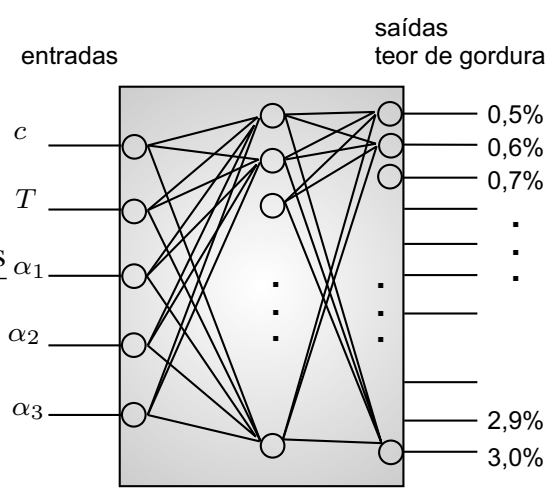

Figura 10: Esquema da rede neural projetada para determinação do teor de gordura, com cinco entradas (temperatura $(T)$, velocidade de propagação $(c)$ e atenuação da onda nas frequências de $4 \mathrm{MHz}\left(\alpha_{1}\right), 5 \mathrm{MHz}\left(\alpha_{3}\right)$ e $\left.6,5 \mathrm{MHz}\left(\alpha_{3}\right)\right)$, uma camada oculta e 26 saídas, com resolução igual a $0,1 \%$. 


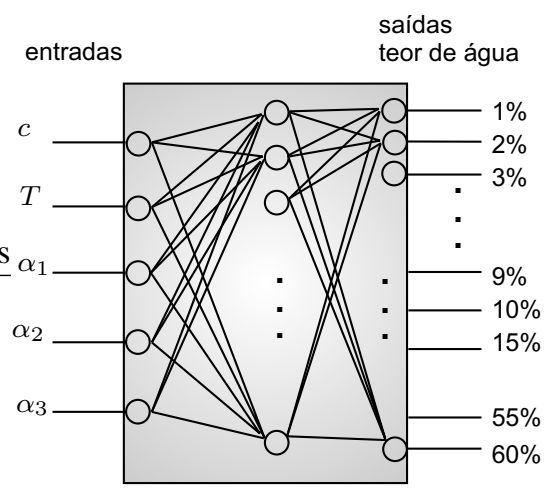

Figura 11: Esquema da rede neural projetada para determinação do teor de água, com cinco entradas (velocidade de propagação, temperatura, coeficiente de atenuação em três frequências), uma camada oculta e 21 saídas, com resolução igual a $1 \%$ (entre 1 e $10 \%$ ) e $5 \%$ (entre 10 e $60 \%$ ).

mada oculta. Redes MLP apresentam um poder computacional muito maior do que aquele apresentado pelas redes sem camadas intermediárias. A precisão obtida e a implementação da função objetivo dependem do número de nodos utilizados nas camadas intermediárias. Contudo, aumentando-se a quantidade de camadas ocultas e o número de nodos, pode ocorrer um efeito indesejado, que é a memorização dos padrões de treinamento, que prejudica a capacidade de extrair as características que possibilitarão o reconhecimento de padrões não vistos durante o treinamento.

Além de variar a quantidade de nodos na camada oculta, variou-se também a taxa de aprendizado das RNAs em 0,01, 0,001 e 0,0001 , e a constante de momento em 0,0002, 0,0008 e 0,0001 . Para a classificação do teor de gordura, variou-se a quantidade máxima de interações em 50000, 100000, 150000 e 200000, enquanto que para a classificação do teor de água adicionada, em 20000, 40000, 50000 e 100000.

O particionamento do conjunto de dados foi tal que $50 \%$ dos padrões de cada classe foram escolhidos aleatoriamente para treinamento, 25\% para validação e $25 \%$ para teste. Isso implicou em que, para o caso da análise do teor de gordura no leite, foram utilizadas 11700 amostras $^{1}$ para treinamento, 5850 para validação e 5859 para teste. Para análise do teor de água adicionada, empregaram-se 9450 amostras para treinamento, 4725 para validação e 4725 para teste. Calcularam-se os erros no conjunto de treinamento e no conjunto de validação, para cada combinação de parâmetros. Para cada topologia usou-se a mesma inicialização de pesos quando variou-se a taxa de aprendizado e o número máximo de iterações e, então, o algoritmo projetado determina a melhor rede, ou seja, a que apresenta o menor erro no conjunto de validação e a

\footnotetext{
${ }^{1}$ Cada amostra aqui signifi ca um conjunto de dados de temperatura, densidade, velocidade de propagação e coefi ciente de atenuação.
}

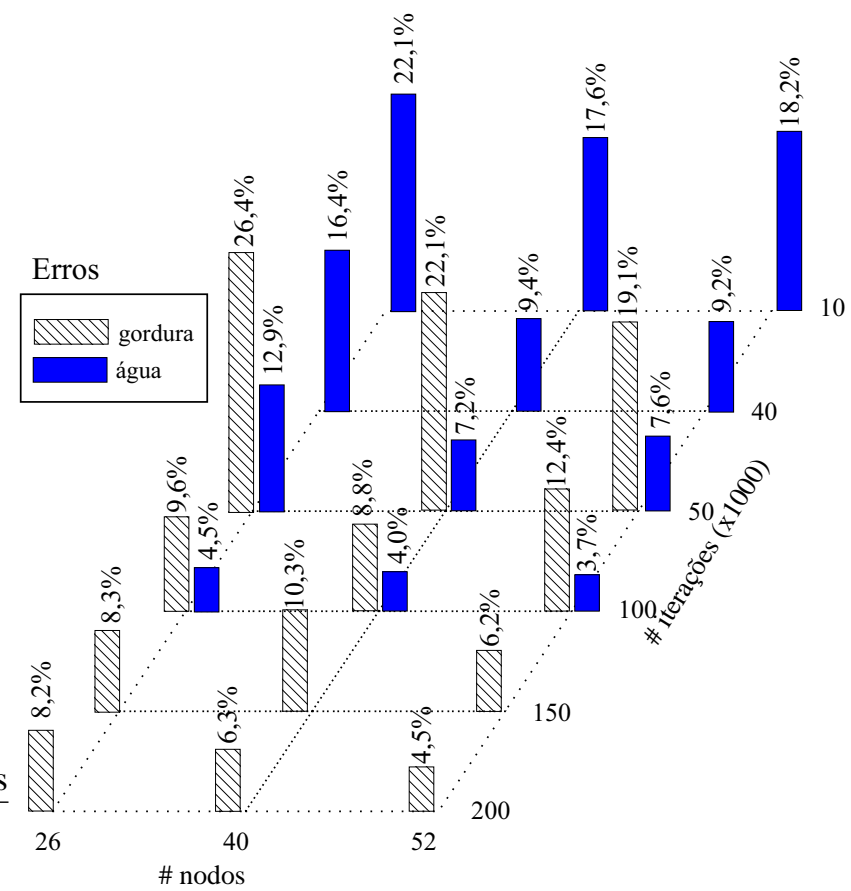

Figura 12: Erros em função do número de nodos e número de iterações para determinação do teor de gordura e quantidade de água adicionada.

menor percentagem de erro.

Na figura 12 mostram-se os resultados de erros das redes neurais projetadas para determinação do teor de gordura e quantidade de água adicionada, com variação do número de nodos da camada oculta e o número máximo de iterações.

Para a determinação da quantidade de gordura, a melhor configuração treinada conseguiu uma classificação correta de $95,5 \%$ e um erro de $4,5 \%$ para a rede com 52 nodos na camada oculta e 200000 iterações. Para detecção de água adicionada ao leite, também foram obtidos resultados com boa capacidade de classificação. As configurações com 40 e 52 nodos na camada oculta obtiveram o maior potencial de classificação. Para a topologia com 40 nodos obteve-se um erro de 4,3\%, sendo assim uma classificação correta de $95,7 \%$. Para a topologia com 52 nodos, obteve-se uma classificação correta de $96,3 \%$ e um erro de $3,7 \%$ sendo que para essa rede o tempo de treinamento foi maior que para a configuração com 40 nodos ocultos.

Também foram realizados testes, com novas aquisições de dados que não foram utilizadas para treinamento nem validação das redes neurais. Esses novos dados (temperatura, velocidade, atenuação) foram armazenados e utilizados como entradas da rede neural e assim avaliadas pela mesma. Os resultados comprovaram a eficácia do algoritmo que obteve 
um potencial de acerto na faixa de 98 a $100 \%$ nos testes para determinação do teor de gordura e de água adicionada, comprovando os resultados da fase de validação.

Como citado anteriormente, em trabalhos de outros autores não foram realizados estudos tão detalhados em relação à preparação de amostras e determinação da resolução do método. Os resultados mostram que o método proposto, utilizando ultra-som e redes neurais, pode alcançar resoluções tão boas quanto ou melhores que de equipamentos comerciais. Como comparação, as resoluções de equipamentos comerciais são: $0,1 \%$ para medição do teor de gordura pelo método de Gerber, cerca de $2 \%$ para medição de teor de água pelo método de crioscópio. O método proposto também poderia reduzir o número de equipamentos necessários para caracterizar ou classificar as amostras, ou ser utilizado como uma primeira avaliação antes de se efetuarem medições de custo mais elevado. Além disso, o ultra-som é uma técnica relativamente robusta e de baixo custo, com fácil implementação quando comparada com as técnicas apresentadas em outros trabalhos.

\section{CONCLUSÕES}

Atualmente, na maioria dos laticínios, as análises da qualidade de leite fluido são realizadas por processos físicoquímicos convencionais, que são demorados, destrutivos e caros. O desenvolvimento de novos equipamentos que possam monitorar com maior facilidade, exatidão e rapidez a matéria-prima vinda do produtor são aspectos importantes que podem contribuir para controlar melhor os padrões de qualidade do produto e para inibir adulterações. Neste trabalho, utilizou-se uma célula de medição por ultra-som para obter dados de densidade, velocidade de propagação e coeficiente de atenuação, que foram relacionados com a concentração de gordura e água adicionada em amostras de leite bovino, medidos também com métodos convencionalmente utilizados em laticínios, para efeito de calibração de amostras e posterior utilização pelas redes neurais artificiais.

A velocidade de propagação é bastante sensível a qualquer um dos parâmetros (teor de gordura e água adicionada), mas que também depende fortemente da temperatura. Sendo assim, medições com temperatura controlada são importantes para se obter resultados confiáveis. A atenuação foi um parâmetro que não sofreu alterações significativas com a variação de temperatura, o que a torna muito importante para o método, apesar de não apresentar a mesma resolução que a velocidade. A densidade não apresentou boa sensibilidade para baixos teores de gordura e água adicionada, e não foi utilizada como entrada das redes neurais.

Observou-se que as redes neurais possibilitaram grande poder de classificação e isso foi comprovado nos experimentos de testes com amostras desconhecidas pelas redes projetadas. Para o problema de adição de água obteve-se um poder de classificação de $96,3 \%$, enquanto que para a obtenção do teor de gordura, $95,5 \%$ de classificação correta.

As técnicas utilizadas permitiram obter uma resolução de $0,1 \%$ na determinação do teor de gordura. Para a determinação do teor de água adicionada (a.a), a resolução foi de $1 \%$ para a faixa entre $1 \%$ e $10 \%$ a.a. e de $5 \%$ para amostras entre $10 \%$ e $60 \%$ a.a. Essas redes foram utilizadas pelo algoritmo, que diagnosticou com sucesso o tipo de leite, pela concentração de gordura e pela quantidade de água adicionada, numa faixa de temperatura entre 25 e $35^{\circ} \mathrm{C}$. Como comparação, as resoluções de equipamentos comerciais são: $0,1 \%$ para medição do teor de gordura pelo método de Gerber, cerca de $2 \%$ para medição de teor de água pelo método de crioscópio. Portanto, os resultados mostram que os métodos por ultra-som e redes neurais são equivalentes aos métodos de Gerber, ponto de congelamento e equipamentos comerciais disponíveis no mercado, com as vantagens de ser uma técnica não destrutiva e que pode substituir diversos equipamentos por apenas um. A parte eletrônica, que nesse caso foi baseada em uma instrumentação de laboratório, pode ser implementada com sistemas dedicados, utilizando pulsadores/receptores integrados, conversores analógico-digitais e processadores, como DSPs (Digital Signal Processors) ou FPGAs (Field Programmable Gate Arrays), o que resultaria em um instrumento relativamente de baixo custo para uso em laticínios.

\section{AGRADECIMENTOS}

À FAPESP pelo financiamento dado ao laboratório de ultrasom e à Capes pelo auxílio ao programa de pós-graduação.

\section{REFERÊNCIAS}

Adamowski, J. C., Buiochi, F., Simon, C., Silva, E. C. N. and Sigelmann, R. A. (1995). Ultrasonic measurement of density of liquids, J. Acoust. Soc. Am. 97(1): 354-361.

Bacaneli, F. (1998). Determinação do teor de gordura no leite através de parâmetros acústicos., Dissertação (mestrado), Escola Politécnica da Universidade de São Paulo, São Paulo.

Behmer, M. L. A. (1984). Tecnologia do Leite, 13 edn, Nobel.

Benedito, J., Carcel, J. A., Gonzales, R. and Mullet, A. (2002). Application of low intensity ultrasonics to cheese manufacturing processes, Ultrasonics 40(1-8): 1923. 
Braga, A. P., Carvalho, A. C. L. F. and Ludemir, T. B. (2000). Redes neurais artificiais: teoria e aplicações, inteligência artificial, $1^{a}$ edn, LTC, Rio de Janeiro.

Brudzewski, K., Osowski, S. and Markiewicz, T. (2004). Classification of milk by means of an electronic nose and svm neural network, Sensors and Actuators $B$ 98(2-3): 291-298.

Chandraratne, M., Kulasiri, D. and Samarasinghe, S. (2008). Classification of lamb carcass using machine vision: Comparison of statistical and neural network analyses, Journal of Food Engineering 82(1): 26-34.

Chen, Q., Zhao, J. and Vittayapadung, S. (2008). Identification of the green tea grade level using electronic tongue and pattern recognition, Food Research International 41(5): 500-504.

Ciosek, P., Brudzewski, K. and Wróblewski, W. (2006). Milk classification by means of an electronic tongue and support vector machine neural network, Meas. Sci. Technol. 17(6): 1379-1384.

Dorabiato, L. F., Maia, J. M. and Gamba, H. R. (2006). Caracterização de leite bovino por ultra-som, XX Congresso Brasileiro de Engenharia Biomédica, São Pedro - SP pp. 788-791.

Dukhin, A. S., Goetz, P. J. and Travers, B. (2005). Use of ultrasound for characterizing dairy products, J. Dairy Science 88(7): 1320-1334.

Elvira, L., Sampedro, L., Mantesanz, J., Gómez-Ullate, Y., Resa, P., Iglesias, J., Echevarría, F. J. and Montero de Espinosa, F. (2005). Non-invasive and non-destructive ultrasonic technique for the detection of microbial contamination in packed UHT milk, Food Research International 38(6): 631-638.

Gunasekaran, S. and Ay, C. (1994). Evaluating milk coagulation with ultrasonics, Food Technology 48(12): 74-78.

Higuti, R. T. and Adamowski, J. C. (2002). Ultrasonic densitometer using a multiple reflection technique, IEEE Trans. Ultras., Ferroelec., Freq. Contr. 49(9): 12601268.

Higuti, R. T., Galindo, B. S., Kitano, C., Buiochi, F. and Adamowski, J. C. (2007). Thermal characterization of an ultrasonic density measurement cell, IEEE Transactions on Instrumentation and Measurement 56(3): 924930.

Javanaud, C. (1988). Applications of ultrasound to food systems, Ultrasonics 26(3): 117-123.
Lewis, E., Sheridan, C., Farrell, M. O., King, D., Flanagan, C., Lyons, W. and Fitzpatrick, C. (2007). Principal component analysis and artificial neural network based approach to analysing optical fibre sensors signals, Sensors and Actuators A - Physical 136(1): 28-38.

Mason, T. J., Paniwnyk, L. and Lorimer, J. (1996). The uses of ultrasound in food technology, Ultrasonics Sonochemistry 3(3): 253-260.

McClements, D. J. (1995). Advances in the application of ultrasound in food analysis and processing, Trends in Food Sci. Technol. 6(9): 293-299.

Miles, C. A., Shore, D. and Langley, K. R. (1990). Attenuation of ultrasound in milks and creams, Ultrasonics 28(6): 394-400.

Povey, M. J. W. (1997). Ultrasonic Techniques for Fluids Characterization, Academic Press, San Diego.

Winquist, F., Krantz-Rulcker, C., Wide, P. and Lundstrom, I. (1998). Monitoring of freshness of milk by an electronic tongue on the basis of voltammetry, Meas. Sci. Technol. 9(12): 1937-1946.

Yua, H., Wanga, J., Yao, C., Zhang, H. and Yu, Y. (2008). Quality grade identification of green tea using e-nose by CA and ANN, LWT - Food Science and Technology 41(7): 1268-1273. 